\title{
Karakteristik psikologis atlet Sea Games Indonesia ditinjau dari jenis cabang olahraga dan jenis kelamin
}

\author{
Yahya Eko Nopiyanto ${ }^{1}$ *, D. Dimyati ${ }^{1}$ \\ ${ }^{1}$ Program Studi Ilmu Keolahragaan, Program Pascasarjana, Universitas Negeri Yogyakarta. \\ Jalan Colombo No. 1, Karangmalang, Yogyakarta, 55281, Indonesia \\ * Corresponding Author. Email: yahyaekonopiyanto@gmail.com \\ Received: 2 December 2016; Revised: 27 December 2017; Accepted: 20 April 2018
}

\begin{abstract}
Abstrak
Penelitian ini bertujuan untuk mengungkapkan: (1) karakteristik psikologis atlet SEA Games Indonesia ditinjau dari cabang olahraga individu, (2) ditinjau dari cabang olahraga tim, (3) perbedaan karakteristik psikologis atlet SEA Games Indonesia ditinjau dari cabang olahraga individu berdasarkan jenis kelamin, dan (4) olahraga tim berdasarkan jenis kelamin. Pendekatan penelitian ini adalah ex-post facto. Penelitian ini merupakan penelitian populasi. Semua subjek dalam populasi diikutsertakan dalam penelitian dengan jumlah 273 atlet. Pengumpulan data menggunakan kuesioner The Psychological Skills Inventory for Sports. Teknik analisis data menggunakan independent sample t-test. Hasil penelitian ini menunjukkan bahwa: (1) karakteristik psikologis atlet SEA Games Indonesia ditinjau dari cabang olahraga individu dalam kategori tinggi (2) ditinjau dari cabang olahraga tim dalam kategori tinggi (3) tidak ada perbedaan yang signifikan karakteristik psikologis atlet SEA Games Indonesia ditinjau dari cabang olahraga individu berdasarkan jenis kelamin dengan nilai sig. $=0,092>0,05$; dan (4) ada perbedaan yang signifikan karakteristik psikologis atlet SEA Games Indonesia ditinjau dari cabang olahraga tim berdasarkan jenis kelamin dengan nilai nilai sig. $=0,000<0,05$.
\end{abstract}

Kata Kunci: karakteristik, psikologis, atlet sea games, jenis cabang olahraga, jenis kelamin

\section{The psychological characteristics of Indonesian Sea Games athletes in terms of sports and sex}

\begin{abstract}
This research was aimed to investigate: (1) the psychological characteristics of Indonesian SEA Games athletes in terms of individual sports, (2) in terms of team sports, (3) the psychological characteristic differences of Indonesian SEA Games athletes in terms of individual sports based on sex, and (4) the psychological characteristic differences of Indonesian SEA Games athletes in terms of team sports based on sex. This research employed the quantitative approach using the survey method with a restrospective causal-comparative design. This research was population research. All subjects in the population were included in this research with a total of 273 athletes. The data were collected using the Psychological Skills Inventory for Sports questionnaire and analyzed using the independent sample $t$ test at. The research findings revealed that: (1) the psychological characteristics of Indonesian SEA Games athletes in terms of individual sports were in a high category, (2) the psychological characteristics of Indonesian SEA Games athletes in terms of team sports are in high category, (3) there were no significant differences in the psychological characteristics of Indonesian SEA Games athletes in terms of individual sports based on sex sig. values $=0.092>0.05$, and (4) there were significant differences in the psychological characteristics of Indonesian SEA Games athletes in terms of team sports based on sex with sig. values $=0.000<0.05$.
\end{abstract}

Keywords: characteristics, psychological, sea games athletes, sports, sex

How to Cite: Nopiyanto, Y., \& Dimyati, D. (2018). Karakteristik psikologis atlet Sea Games Indonesia ditinjau dari jenis cabang olahraga dan jenis kelamin. Jurnal Keolahragaan, 6(1), 69-76. doi:http://dx.doi.org/10.21831/jk.v6i1.15010 


\section{PENDAHULUAN}

Indonesia menjadi salah satu negara yang berpartisipasi aktif dalam SEA Games. Namun daya saing Indonesia di tingkat Asia Tenggara terasa semakin merosot. Sejak keikutsertaannya pada SEA Games IX/1977, Indonesia hampir dipastikan menjadi juara umum. Akan tetapi sejak SEA Games XX/1999, dominasi Indonesia telah memudar. Thailand telah menggeser posisi Indonesia dan posisi Vietnam yang pada SEA Games XXI/2001 membayangi Indonesia, pada SEA Games XXII 2003 dan SEA Games XXIII/ 2005 telah mengungguli Indonesia (Maksum, 2007, p.1).

Banyak faktor yang mempengaruhi prestasi Indonesia di SEA Games. Penulis meyakini bahwa faktor psikologis atlet Indonesia mempunyai peranan penting dalam peningkatan prestasi olahraga. Keberhasilan dan kegagalan pemain dalam olahraga prestasi sangat ditentukan oleh perpaduan dari kemampuan faktor fisik dan mental. Para pelatih meyakini bahwa tidak kurang dari $50 \%$ keberhasilan dalam olahraga ditentukkan oleh faktor mental, bahkan untuk cabang olahraga seperti golf, tenis, dan figure skating faktor mental tersebut mencapai 80 sampai $90 \%$ (Weinberg \& Gould, 2011, p.248).

Beberapa hasil penelitian menyatakan bahwa terdapat perbedaan karakteristik psikologis atlet pada cabang olahraga individu dan tim. Olahraga individu mempunyai tingkat percaya diri yang lebih tinggi daripada olahraga tim (Gillet \& Rosnet, 2008). Olahraga individu dan tim mempunyai perbedaan dari segi kecemasan dan usaha (Cooke, Kavussanu, McIntyre, \& Ring, 2013). Berdasarkan beberapa hasil penelitian yang telah dilakukan dapat disimpulkan bahwa terdapat perbedaan karakteristik psikologi antara olahraga individu dan olahraga tim. Adanya perbedaan yang mendasar mengenai karakteristik masing-masing cabang olahraga tersebut memungkinkan terjadinya perbedaan karakteristik psikologis atlet. Setiap cabang olahraga memiliki karakteristik berbeda-beda, mulai dari aktivitas gerak tubuh, peraturan yang digunakan dalam cabang olahraga dan perilaku atlet dari yang ditimbulkan dari setiap cabang olahraga akan membentuk karakteristik yang berbeda (Hermawati, 2014, p.3).

Perbedaan tersebut juga dikarenakan oleh jenis kelamin. Jenis kelamin merupakan faktor utama yang mempengaruhi penampilan terbaik dan rekor dunia (Thibault, et al., 2010, p.214). Atlet yang mempunyai penampilan terbaik dan dapat dipastikan mempunyai karakteristik psikologis yang baik. Karakteristik psikologis tersebut dapat dipengaruhi oleh jenis kelamin. Atlet laki-laki mempunyai motivasi yang lebih tinggi jika dibandingkan dengan atlet perempuan (Deaner, Balish \& Lombardo, 2016).

Kunci perbedaan antara penampilan yang baik dan penampilan yang buruk adalah terletak pada tingkatan keterampilan psikologis pemain yang lebih baik dibandingkan dengan keterampilan fisik (Dosil, 2006). Itu tidak berarti bahwa keterampilan psikologis lebih penting dari fisik, taktik atau teknik. Semua aspek tersebut penting dan harus dilakukan latihan secara rutin.

Berdasarkan pendapat para ahli dapat disimpulkan bahwa faktor psikologis mempunyai peranan penting. Dalam cakupan yang lebih spesifik penulis menyatakan bahwa karakteristik psikologi atlet Indonesia menjadi kata kunci dalam upaya peningkatan prestasi olahraga. Pengetahuan dan pemahaman tentang karakteristik psikologis atlet yang terkait dan mendukung dalam rangka pembinaan atlet Indonesia sangat penting diketahui oleh para pelatih dan pembina olahraga untuk membantu atlet agar dapat berprestasi optimal di SEA Games ke-29 tahun 2017.

Berdasarkan pengetahuan penulis sampai sekarang ini belum ada data yang mengambarkan dan menjelaskan tentang karakteristik psikologis atlet SEA Games Indonesia ditinjau dari cabang olahraga individu, olahraga tim, dan jenis kelamin. Permasalahan mengenai aspek psikologis dan karakteristik psikologis atlet Indonesia perlu dikaji lebih lanjut supaya dapat meningkatkan prestasi olahraga. Oleh karena itu penelitian ini akan memfokuskan pada atlet Indonesia yang akan berpartisipasi di SEA Games ke-29 tahun 2017 dengan judul "karakteristik psikologis atlet SEA Games Indonesia ditinjau dari jenis cabang olahraga dan jenis kelamin".

Karakteristik psikologis yaitu aspek-aspek psikologis yang melekat pada diri atlet SEA Games Indonesia ditinjau dari cabang olahraga individu dan tim. Karakteristik psikologis terdiri dari motivasi, kepercayaan diri, kontrol kecemasan, persiapan mental, pentingnya tim, dan konsentrasi.

Motivasi berasal dari bahasa latin yaitu 'motus' yang mengandung arti "move". Jadi motivasi berarti menggerakkan atau mendorong untuk bergerak (Chasmore, 2008, p.287). Menurut Gunarsa (2008, p.47) "motivasi dapat diartikan sebagai suatu kekuatan atau tenaga pendorong untuk melakukan suatu hal atau 
menampilkan sesuatu perilaku tertentu". Motivasi adalah energi psikologis yang bersifat abstrak dan wujudnya hanya dapat diamati dalam bentuk manifestasi tingkah laku yang ditampilkan individu. Dalam hubungan ini, motivasi sebagai proses psikologis merupakan refleksi kekuatan interaksi antara kognisi, pengalaman dan kebutuhan (Husdarta, 2010, p.31) .

Demikian juga, menurut Wongso dalam Komarudin (2015, p.22) "jika atlet memiliki kemauan kuat untuk sukses, 50 persen kesuksesan sudah di tangan". Tambahan lagi, motivasi merupakan keterampilan mental yang bersifat mendasar yang perlu dimilki oleh atlet. Jadi, yang dimaksud motivasi berolahraga dalam tulisan ini adalah tenaga pendorong untuk menampilkan sesuatu perilaku tertentu dalam olahraga dan merupakan refleksi kekuatan interaksi antara kognisi, pengalaman dan kebutuhan.

Kepercayaan diri merupakan salah satu aspek kepribadian yang merupakan modal dasar dan terbentuk melalui proses latihan dan interaksi dengan lingkungan sosial. Menurut Husdarta (2010, p.92) salah satu modal utama dan syarat mutlak untuk mencapai prestasi olahraga yang gemilang adalah memiliki percaya diri.

Kepercayaan dalam olahraga didefinisikan sebagai tingkat kepastian yang dimiliki oleh individu tentang kemampuan mereka untuk menjadi sukses dalam olahraga (Lane, 2008). Sedangkan menurut Weinberg dan Gould (2011, p.320), kepercayaan diri diartikan sebagai keyakinan bahwa anda dapat berhasil melakukan perilaku yang diinginkan. Percaya diri adalah keyakinan individu tentang kemampuan dan atau harapan untuk mencapai keberhasilan berdasarkan kemampuannya (Brewer, 2007, p.43). Berdasarkan uraian tersebut disimpulkan bahwa kepercayaan diri dalam konteks olahraga adalah keyakinan yang dimiliki oleh atlet untuk menjadi sukses dalam olahraga.

Kecemasan adalah keadaan negatif yang ditandai dengan gugup, khawatir, dan ketakutan dan terkait dengan aktivasi gairah tubuh (Weinberg \& Gould, 2011, p.77). Sedangkan menurut LeUnes (2011) kecemasan adalah "bagian dari aurosal, dan ditandai oleh ketidakpastian, ketidaknyamanan, ketakutan, dan rasa takut yang tidak diketahui". Jadi yang dimaksud kontrol kecemasan dalam penelitian ini adalah kemampuan atlet untuk mengendalikan perasaan kekhawatiran, ketakutan, gugup, ketidakpastian, ketidaknyamanan terhadap kemungkinankemungkinan yang akan terjadi.
Persiapan mental wajib dilakukan sebelum, selama dan sesudah menghadapi pertandingan. Persiapan mental adalah strategi atlet dan tim dalam semua aspek kognitif, emosi, dan perilaku yang digunakan untuk mendapatkan penampilan serta kondisi psikologis yang optimal dalam kompetisi atau latihan (Brewer, 2007, p.53). Persiapan mental yang perlu dilakukan sejak awal adalah kontrol terhadap arousal, kepercayaan diri, pemeliharaan fokus, kontrol terhadap gangguan, dan penetapan tujuan (Ryba dalam Tenenbaum \& Eklund, 2007, p.? ).

Tim adalah kelompok orang yang harus berinteraksi satu sama lain untuk mencapai tujuan bersama (Weinberg \& Gould, 2011, p.160). Jadi, yang dimaksud dengan pentingnya tim dalam penelitian ini adalah suatu tindakan yang dilakukan oleh atlet dimana mengutamakan proses kesatuan dan kebersamaan sehingga memungkinkan tim dapat bekerja dengan baik dan efektif.

Konsentrasi merupakan salah satu faktor psikologis yang berpengaruh terhadap penampilan atlet. Menurut Gunarsa (2008, p.8) "konsentrasi diartikan sebagai perhatian yang terpusat terhadap suatu objek untuk jangka waktu tertentu". Konsentrasi sangat penting peranannya dalam olahraga karena jika terganggu maka akan timbul masalah, terutama pada aktivitas olahraga yang memerlukan akurasi lemparan, pukulan, tendangan dan tembakan pada sasaran.

Beberapa hasil penelitian menyatakan bahwa ada perbedaan karakteristik psikologis atlet pada cabang olahraga individu dan tim. Olahraga individu mempunyai tingkat percaya diri yang lebih tinggi daripada olahraga tim (Gillet \& Rosnet, 2008). Berdasarkan beberapa hasil penelitian yang telah dilakukan dapat disimpulkan bahwa terdapat perbedaan karakteristik psikologi antara olahraga individu dan olahraga tim. Adanya perbedaan yang mendasar mengenai karakteristik masing-masing cabang olahraga tersebut memungkinkan terjadinya perbedaan karakteristik psikologis atlet. Setiap cabang olahraga memiliki karakteristik berbedabeda, mulai dari aktivitas gerak tubuh, peraturan yang digunakan dalam cabang olahraga dan perilaku atlet dari yang ditimbulkan dari setiap cabang olahraga akan membentuk karakteristik yang berbeda (Hermawati, 2014).

Perbedaan tersebut juga dikarenakan oleh jenis kelamin. Beberapa penelitian menyatakan bahwa ada perbedaan karakteristik psikologis antara atlet laki-laki dan perempuan. Atlet lakilaki lebih baik dalam mengontrol emosi dan 
relaksasi sedangkan atlet perempuan kurang baik dalam mengontrol emosi dan relaksasi (Katsikas, Argeitaki, Smirniotou, 2009, p.29). Atlet lakilaki mempunyai tingkat kecemasan yang lebih rendah jika dibandingkan dengan atlet perempuan (Parnabas, 2015, p.23).

Hasil penelitian lebih menggambarkan dan menekankan pada atlet di luar negeri. Sementara itu kajian tentang karakteristik psikologis atlet SEA Games dan kaitannya dengan prestasi atlet Indonesia selama ini belum ada. Penulis meyakini bahwa ada perbedaan karakteristik psikologis atlet SEA Games ditinjau dari cabang olahraga individu, olahraga tim, dan jenis kelamin. Inilah yang akan dijelaskan dan dicari kebenarannya dalam penelitian ini. Pengetahuan dan pemahaman tentang karakteristik psikologis atlet yang terkait dan mendukung dalam rangka pembinaan atlet Indonesia sangat penting diketahui oleh para pelatih dan pembina olahraga untuk membantu atlet agar dapat berprestasi optimal di SEA Games ke-29 tahun 2017.

Berdasarkan pengetahuan penulis sampai sekarang ini belum ada data yang mengambarkan dan menjelaskan tentang karakteristik psikologis atlet SEA Games Indonesia ditinjau dari cabang olahraga individu, olahraga tim, dan jenis kelamin. Permasalahan mengenai aspek psikologis dan karakteristik psikologis atlet Indonesia perlu dikaji lebih lanjut supaya dapat meningkatkan prestasi olahraga. Oleh karena itu penelitian ini akan memfokuskan pada atlet Indonesia yang akan berpartisipasi di SEA Games ke-29 tahun 2017 dengan judul "karakteristik psikologis atlet SEA Games Indonesia ditinjau dari jenis cabang olahraga dan jenis kelamin".

Penelitian ini bertujuan untuk mengetahui: karakteristik psikologis atlet SEA Games Indonesia ditinjau dari cabang olahraga individu, karakteristik psikologis atlet SEA Games Indonesia ditinjau dari cabang olahraga tim, perbedaan karakteristik psikologis atlet SEA Games Indonesia ditinjau dari cabang olahraga individu berdasarkan jenis kelamin, perbedaan karakteristik psikologis atlet SEA Games Indonesia ditinjau dari cabang olahraga tim berdasarkan jenis kelamin.

\section{METODE}

Jenis penelitian yang digunakan dalam penelitian ini adalah kuantitatif menggunakan metode survei dengan desain penelitian $a$ restrospective causal-comparative design (Mills, \& Gay, 2016) atau ex-post facto merupakan penelitian yang berusaha untuk menentukan penyebab atau alasan adanya perbedaan karakteristik psikologis atlet SEA Games ditinjau dari jenis cabang olahraga dan jenis kelamin.

Penelitian ini dilaksanakan di Yogyakarta, Jakarta, Bandung, Solo dan Bali pada bulan Februari sampai April 2017. Penelitian ini mengumpulkan data dengan cara membagikan kuesioner kepada sampel yaitu atlet Indonesia yang akan mengikuti SEA Games ke-29 tahun 2017.

Atlet yang akan mengikuti SEA Games ke29 tahun 2017 dan telah mendapatkan surat keputusan dari Satuan Pelaksana Program Indonesia Emas. Semua subjek dalam populasi diikutsertakan dalam penelitian dengan jumlah 273 atlet yang terdiri dari 112 atlet laki-laki dan 78 atlet perempuan ditinjau dari cabang olahraga individu, sedangkan 43 atlet laki-laki dan 40 atlet perempuan ditinjau dari cabang olahraga tim.

Data dalam penelitian ini adalah numerik atau rasio dan dikumpulkan melalui instrumen berupa kuesioner "The Psychological Skills Inventory for Sports (PSIS) yang dikembangkan oleh Mahoney, Gabriel, dan Perkin (1987) yang terdiri atas motivasi, kepercayaan diri, kontrol kecemasan, persiapan mental, pentingnya tim, dan konsentrasi.

Tabel 1. Isi Instrumen The Psychological Skill Inventory for Sports

\begin{tabular}{clc}
\hline Variabel & \multicolumn{1}{c}{ Aspek } & $\begin{array}{c}\text { Jumlah } \\
\text { Item }\end{array}$ \\
\hline Karakteristik & Motivasi & 8 \\
Psikologis & Kepercayaan Diri & 7 \\
& Kontrol Kecemasan & 7 \\
& Persiapan Mental & 6 \\
& Pentingnya Tim & 4 \\
& Konsentrasi rral & 6 \\
& & 38 \\
\hline
\end{tabular}

Tabel 2. Bobot Nilai Alternatif Jawaban

\begin{tabular}{lcc}
\hline Alternatif Jawaban & $\begin{array}{c}\text { Bobot } \\
\text { Pernyataan } \\
\text { Positif }\end{array}$ & $\begin{array}{c}\text { Bobot } \\
\text { Pernyataan } \\
\text { Negatif }\end{array}$ \\
\hline Selalu & 5 & 1 \\
Sering & 4 & 2 \\
Kadang-Kadang & 3 & 3 \\
Sangat Jarang & 2 & 4 \\
Tidak Pernah & 1 & 5 \\
\hline
\end{tabular}

Sebelum digunakan pada penelitian sesungguhnya ada beberapa tahapan yang perlu dilakukan yaitu: Pertama, validasi isi. Validasi isi melalui expert judgment yang ahli di bidangnya. Kedua, ujicoba instrumen. Ujicoba instrumen digunakan untuk seleksi item. Caranya dengan mengkorelasikan skor setiap item dengan skor 
total item. Uji coba instrumen dilakukan pada atlet Daerah Istimewa Yogyakarta yang pernah mendapatkan medali emas di Pekan Olahraga Nasional (PON) berjumlah 76 atlet terdiri dari berbagai cabang olahraga. Alasan memilih atlet DIY sebagai sampel ujicoba adalah atlet tersebut mempunyai karakteristik psikologis yang hampir sama dengan atlet SEA Games karena atlet yang dipersiapkan untuk SEA Games 2017 berasal dari atlet PON yang mendapatkan medali emas. Ketiga, membuat kriteria kategori karakteristik psikologis atlet berdasarkan nilai rerata ideal dan standar deviasi ideal dengan menggunakan rumus sebagai berikut:

$$
M i=\frac{(S T+S R)}{2} \quad S D i=\frac{(S T-S R)}{6}
$$

Tabel 3. Rumus Penentuan Kriteria (Wagiran, 2015, p.337)

\begin{tabular}{lc}
\hline \multicolumn{1}{c}{ Interval } & Kategori \\
\hline di atas (Mi + 1,8SD) s.d. (M i+ 3SD) & $\mathrm{ST}$ \\
di atas (Mi 0,6) S.d. (Mi + 1,8SD) & $\mathrm{T}$ \\
di atas (M -0,6SD) s.d. (Mi + 0,6SD) & $\mathrm{S}$ \\
di atas (Mi-1,8SD) s.d. (Mi - 0,6SD) & $\mathrm{R}$ \\
(Mi-3SD ) s.d. ( Mi-1,8SD) & SR \\
\hline
\end{tabular}

Berdasarkan hasil perhitungan menggunakan rumus pada Tabel 3, maka kriteria kategori karakteristik psikologis atlet adalah sebagai berikut:

Tabel 4. Kriteria Aspek Motivasi

\begin{tabular}{lc}
\hline \multicolumn{1}{c}{ Interval } & Kategori \\
\hline di atas 33,59 s.d. 40 & Sangat Tinggi \\
di atas 27,20 s.d. 33,59 & Tinggi \\
di atas 20,80 s.d. 27,20 & Sedang \\
di atas 14,40 s.d. 20,80 & Rendah \\
8 s.d. 14,40 & Sangat Rendah \\
\hline
\end{tabular}

Tabel 5. Kriteria Aspek Kepercayaan Diri

\begin{tabular}{lc}
\hline \multicolumn{1}{c}{ Interval } & Kategori \\
\hline di atas 29,41 s.d. 35 & Sangat Tinggi \\
di atas 23,80 s.d. 29,41 & Tinggi \\
di atas 18,80 s.d. 23,80 & Sedang \\
di atas 12,59 s.d. 18,80 & Rendah \\
7 s.d. 12,59 & Sangat Rendah \\
\hline
\end{tabular}

Tabel 6. Kriteria Aspek Kontrol Kecemasan

\begin{tabular}{lc}
\hline \multicolumn{1}{c}{ Interval } & Kategori \\
\hline di atas 29,41 s.d. 35 & Sangat Tinggi \\
di atas 23,80 s.d. 29,41 & Tinggi \\
di atas 18,80 s.d. 23,80 & Sedang \\
di atas 12,59 s.d. 18,80 & Rendah \\
7 s.d. 12,59 & Sangat Rendah \\
\hline
\end{tabular}

Tabel 7. Kriteria Aspek Persiapan Mental

\begin{tabular}{lc}
\hline \multicolumn{1}{c}{ Interval } & Kategori \\
\hline di atas 25,2 s.d. 30 & Sangat Tinggi \\
di atas 20,4 s.d. 25,2 & Tinggi \\
di atas 15,6 s.d. 20,4 & Sedang \\
di atas 10,8 s.d. 15,6 & Rendah \\
6 s.d. 10,8 & Sangat Rendah \\
\hline
\end{tabular}

Tabel 8. Kriteria Aspek Pentingnya Tim

\begin{tabular}{lc}
\hline \multicolumn{1}{c}{ Interval } & Kategori \\
\hline di atas 16,81 s.d. 20 & Sangat Tinggi \\
di atas 13,60 s.d. 16,81 & Tinggi \\
di atas 10,40 s.d. 13,60 & Sedang \\
di atas 7,19 s.d. 10,40 & Rendah \\
4 s.d. 7,19 & Sangat Rendah \\
\hline
\end{tabular}

Tabel 9. Kriteria Aspek Konsentrasi

\begin{tabular}{lc}
\hline \multicolumn{1}{c}{ Interval } & Kategori \\
\hline di atas 25,2 s.d. 30 & Sangat Tinggi \\
di atas 20,4 s.d. 25,2 & Tinggi \\
di atas 15,6 s.d. 20,4 & Sedang \\
di atas 10,8 s.d. 15,6 & Rendah \\
6 s.d. 10,8 & Sangat Rendah \\
\hline
\end{tabular}

\section{Teknik Analisis Data}

Teknik analisis data menggunakan bantuan Statistical Product and Service Solution (SPPS) versi 23.0. Adapun langkah-langkah yang digunakan penulis untuk menganalisis data yaitu sebagai berikut: mengelompokkan data berdasarkan variabel dan jenis responden, menyajikan data dari variabel yang diteliti, membuat kriteria kategori karakteristik psikologis atlet, melakukan analisis data untuk menguji hipotesis yang telah diajukan, melakukan analisis data untuk menjawab rumusan masalah.

Statistik inferensial independent sample $t$ test untuk menganalisis: perbedaan karakteristik psikologis atlet SEA Games Indonesia ditinjau dari cabang olahraga individu berdasarkan jenis kelamin, perbedaan karakteristik psikologis atlet SEA Games Indonesia ditinjau dari cabang olahraga tim berdasarkan jenis kelamin.

\section{HASIL DAN PEMBAHASAN}

\section{Karakteristik Psikologis Atlet SEA Games Indonesia Ditinjau dari Cabang Olahraga Individu}

Karakteristik psikologis atlet SEA Games Indonesia ditinjau dari cabang olahraga individu pada aspek motivasi termasuk dalam kategori sangat tinggi dengan rerata sebesar 36,35; aspek kepercayaan diri termasuk dalam kategori tinggi sebesar 27,89; aspek kontrol kecemasan termasuk dalam kategori tinggi dengan nilai rerata 
sebesar 25,07; aspek persiapan mental termasuk dalam kategori tinggi dengan nilai rerata sebesar 22,92 ; aspek pentingnya tim termasuk dalam kategori tinggi dengan nilai rerata sebesar 14,24; aspek konsentrasi termasuk dalam kategori tinggi dengan nilai rerata sebesar 21,91.

\section{Karakteristik Psikologis Atlet SEA Games Indonesia Ditinjau dari Cabang Olahraga Tim}

Karakteristik psikologis atlet SEA Games Indonesia ditinjau dari cabang olahraga tim pada aspek motivasi termasuk dalam kategori sangat tinggi dengan nilai rerata sebesar 35,46; aspek kepercayaan diri termasuk dalam kategori tinggi dengan nilai rerata sebesar 26,51; aspek kontrol kecemasan termasuk dalam kategori tinggi dengan nilai rerata sebesar 24,18; aspek persiapan mental termasuk dalam kategori tinggi dengan nilai rerata sebesar 21,32 ; aspek pentingnya tim termasuk dalam kategori tinggi dengan nilai rerata sebesar 15,17; aspek konsentrasi termasuk dalam kategori tinggi dengan nilai rerata sebesar 22,30.

Perbedaan Karakteristik Psikologis Atlet SEA Games Indonesia Ditinjau dari Cabang Olahraga Individu Berdasarkan Jenis Kelamin.

Tabel. Hasil Uji t Cabang Olahraga Individu

\begin{tabular}{|c|c|c|c|c|}
\hline \multicolumn{5}{|c|}{ Levane's Test } \\
\hline $\mathrm{F}$ & Sig. & $\mathrm{t}$ & df & Sig.2 tailed \\
\hline 2,496 & 0,116 & 1,309 & 188 & 0,192 \\
\hline
\end{tabular}

Berdasarkan hasil analisis data dapat diketahui bahwa nilai rerata atlet laki-laki dari cabang olahraga individu sebesar 149,1339 dan atlet perempuan sebesar 146,6667 serta $\mathrm{t}$ hitung $=$ 1,309 dengan nilai sig.sebesar 0,0192 dimana $0,092>0,05$ maka Ho diterima. Jadi dapat disimpulkan bahwa pada taraf signifikan 0,05 tidak ada perbedaan yang signifikan karakteristik psikologis atlet SEA Games Indonesia ditinjau dari cabang olahraga individu berdasarkan jenis kelamin.

Hasil penelitian sebelumnya juga menyatakan bahwa tidak ada perbedaan yang signifikan karakteristik psikologis atlet laki-laki dan perempuan ditinjau dari cabang olahraga individu. Hasil penelitian Hussain, Zaman \& Idris (2014, p.82) menyatakan bahwa tidak ada perbedaan yang signifikan antara atlet laki-laki (360 atlet) dan perempuan (360 atlet) ditinjau dari cognitive anxiety, somatic anxiety and self-confidence dalam cabang olahraga individu (tenis meja tunggal, bulutangkis tunggal, dan atletik) maupun tim (bolavoli, bolabasket, bola tangan). Penelitian yang dilakukan oleh Uçan, \& Çağlayan (2012, p.279) juga menemukan bahwa tidak ada perbedaan yang signifikan antara atlet laki-laki (49 atlet) dan perempuan (52 atlet) ditinjau dari selfesteem dalam cabang olahraga individu (renang, senam, rowing, panahan dan atletik).

Penyebab terjadinya tidak ada perbedaan yang signifikan karakteristik psikologis atlet $S E A$ Games Indonesia ditinjau dari cabang olahraga individu berdasarkan jenis kelamin dapat dijelaskan melalui teori. Secara teoritis atlet laki-laki dan perempuan mempunyai orientasi tujuan yang sama dalam olahraga (Deaner, Carter, Joyner, \& Hunter, 2015). Karena adanya tujuan yang jelas dalam mengikuti olahraga maka akan menuntun atlet laki-laki dan perempuan ditinjau dari cabang olahraga individu untuk mengembangkan psikologis yang dimiliki untuk menunjang kesuksesan dalam bidang olahraga yang diikutinya.

Secara teoritis perempuan telah membuat langkah yang luar biasa untuk berpartisipasi di bidang olahraga. Hal ini dapat dilihat dari peningkatan jumlah atlet perempuan yang terlibat dalam pertandingan dan prestasi atlet perempuan di SEA Games. Sampel atlet perempuan dalam penelitian ini lebih dari $51 \%$ telah berpartisipasi dan $49 \%$ pernah menjadi juara sedangkan atlet laki-laki kurang dari $50 \%$ telah berpartisipasi dan $41 \%$ pernah menjadi juara di SEA Games. Dapat dianalogikan bahwa atlet yang berprestasi di $S E A$ Games dipastikan mempunyai karakteristik psikologis yang baik terdiri dari motivasi, kepercayaan diri, kontrol kecemasan, persipan mental, pentingnya tim dan konsentrasi. Jadi tidak mengejutkan jika hasil dari penelitian ini menemukan bahwa tidak ada perbedaan yang signifikan karakteristik psikologis atlet SEA Games Indonesia ditinjau dari cabang olahraga individu berdasarkan jenis kelamin. Hal ini terjadi karena atlet laki-laki dan atlet perempuan SEA Games Indonesia mempunyai karakteristik psikologis yang sama baiknya.

Teori lain yang dapat menjelaskan penyebab terjadinya tidak ada perbedaan yang signifikan karakteristik psikologis atlet SEA Games Indonesia ditinjau dari cabang olahraga individu berdasarkan jenis kelamin dapat dijelaskan melalui teori Bandura yang dikenal dengan teori kognitif sosial. Teori ini mendeskripsikan manusia sebagai organisme yang dinamis dalam memproses informasi dan sebagai organisme sosial (Hergenhahn \& Olson, 2015, p.383). Kebanyakan proses belajar manusia melibatkan orang lain dalam lingkungan sosial. Berdasarkan observasi dan interaksi dengan 
orang lain inilah kognisi manusia, termasuk standar penampilan dan penilaian moral terus berkembang.

Menurut teori ini, manusia mempunyai empat ciri. Pertama, ciri intensionalitas yang didefinisikan sebagai "representasi arah tindakan yang akan dilakukan di masa depan". Dengan kata lain, intensionalitas melibatkan perencanaan arah tindakan untuk tujuan tertentu. Adanya kemampuan untuk merencanakan arah masa depan yang baik sehingga menuntun atlet lakilaki dan perempuan untuk melakukan tindakan terbaiknya agar menjadi juara di SEA Games.

Kedua, manusia mempunyai pemikiran ke depan. Artinya manusia mempunyai kemampuan untuk mengantisipasi atau memperkiraan konsekuensi dari niat seseorang. Orientasi ke masa depan ini memandu perilaku manusia ke arah hasil positif dan menjauhkan diri dari hasil negatif. Atlet laki-laki dan perempuan telah menyadari konsekuensi dari setiap tindakan yang dilakukan. Setiap atlet mempunyai keinginan untuk menjadi juara dan berusaha untuk menghindari kekalahan di SEA Games. Hal inilah yang memandu atlet laki-laki dan perempuan untuk memotivasi dirinya, meningkatkan kepercayaan diri dan konsentrasi agar keinginan menjadi juara dapat tercapai.

Ketiga, manusia mempunyai kereaktifandiri. Artinya manusia mempunyai kemampuan untuk menghubungkan pikiran dan tindakan. Bandura dalam Hergenhahn \& Olson (2015, p.384) menyatakan bahwa "manusia melakukan hal-hal yang membuat mereka puas, rasa bangga, dan bermanrtabat, dan tak mau berbuat sesuatu yang menimbulkan kekecewaan, merendahkan diri, dan memalukan diri". Jadi, faktor kecakapan, keyakinan, dan nilai dalam teori kognitif sosial bertindak sebagai pemberi pedoman. Atlet laki-laki dan perempuan akan terus memotivasi dirinya untuk menjadi juara di SEA Games sesuai dengan olahraga yang ditekuninya agar memperoleh rasa puas, bangga dan bermartabat.

Keempat, manusia mempunyai ciri kereflektifan diri. Artinya manusia mempunyai kemampuan metakognisi untuk merenungkan arah, konsekuensi, dan makna dari rencana dan tindakan. Bandura dalam Hergenhahn \& Olson (2015, p.385) menyatakan bahwa "keyakinan tentang kecakapan adalah dasar dari manusia". Kecakapan diri adalah faktor terpenting yang menentukan pilihan tindakan manusia, intensitas aktivitas, kemampuan bertahan saat menghadapi rasa frustasi yang bisa menimbulkan kegagalan. Atlet laki-laki dan perempuan di SEA Games
Indonesia mempunyai kemampuan yang sama untuk mengatasi rasa frustasi dan stress ketika mengalami kegagalan.

Berdasarkan keempat ciri yang dikemukakan oleh Bandura (2008) dapat dianalogikan bahwa atlet SEA Games Indonesia mempunyai arah tindakan yang jelas untuk menjadi juara. Hal ini menuntun atlet untuk lebih termotivasi dalam melakukan latihan, meningkatkan kepercayaan diri dalam setiap latihan, melatih kontrol kecemasan agar mengurasi rasa cemas dalam setiap pertandingan, melakukan persiapan fisik, teknik, taktik, psikologis dengan baik, mementingkan tujuan bersama, dan melatih konsentrasi yang dibutuhkan untuk memenangkan pertandingan dan menjadi juara.

Adanya keempat sifat yang dimiliki manusia menurut teori Bandura menjadikan tidak ada perbedaan yang signifikan karakteristik psikologis atlet SEA Games Indonesia ditinjau dari cabang olahraga individu berdasarkan jenis kelamin. Atlet laki-laki dan perempuan mempunyai tujuan yang sama yaitu menjadi juara di SEA Games Malaysia tahun 2017. Kesamaan tujuan inilah yang menuntun atlet untuk berlatih keras dan berusaha untuk meningkatkan motivasi, kepercayaan diri, kontrol kecemasan, persiapan mental, pentingnya tim, dan konsentrasi.

\section{Perbedaan Karakteristik Psikologis Atlet SEA Games Indonesia Cabang Olahraga Tim Berdasarkan Jenis Kelamin}

Tabel. Hasil Uji t Cabang Olahraga Tim

\begin{tabular}{lllll}
\hline \multicolumn{4}{l}{ Levane's Test } \\
\hline $\mathrm{F}$ & Sig. & $\mathrm{t}$ & $\mathrm{df}$ & Sig.2 tailed \\
\hline 0,003 & 0,985 & 3,948 & 81 & 0,000 \\
\hline
\end{tabular}

Berdasarkan hasil analisis data dapat diketahui bahwa nilai rerata atlet laki-laki ditinjau dari cabang olahraga tim sebesar 150,1395 dan atlet perempuan sebesar 139,3500 serta nilai $t$ hitung $=3,948$ dengan nilai sig. $=0,000$ dimana $0,000<0,05$ maka Ho ditolak. Jadi dapat disimpulkan bahwa pada taraf signifikan 0,05 ada perbedaan yang signifikan karakteristik psikologis atlet cabang olahraga tim berdasarkan jenis kelamin.

Perbedaan tersebut dipengaruhi oleh kontrol kecemasan. Kontrol kecemasan atlet perempuan SEA Games Indonesia ditinjau dari cabang olahraga tim masuk kategori sedang dan atlet laki-laki masuk kategori tinggi. Artinya atlet perempuan mempunyai kontrol kecemasan yang lebih rendah jika dibandingkan dengan atlet lakilaki. Hal ini sesuai dengan hasil penelitian yang 
menyatakan bahwa atlet perempuan memiliki kecenderungan untuk menggunakan emosi yang menciptakan lebih banyak stress (Anshel, Porter \& Quek dalam Hoiness, Weathington \& Cotrell, 2008, p.2). Contohnya, perempuan lebih cenderung menginternalisasi kecemasan dan terus memutar ulang atau menganalisis kesalahan lebih banyak jika dibandingkan dengan laki-laki.

Kebanyakan atlet perempuan mempunyai masalah dengan konflik peran yang melekat pada dirinya. Selain itu, atlet perempuan harus menyeimbangkan peran dirinya di dalam masyarakat. Lance (2004) menemukan bahwa karena konflik yang bertambah atlet perempuan mempunyai konflik yang lebih banyak jika dibandingkan dengan atlet laki-laki. Konflik juga ditemukan lebih umum untuk atlet perempuan yang berpartisipasi dalam olahraga tradisional maskulin seperti baseball, sepakbola, soccer, hoki, dan basket.

Berdasarkan hasil penelitian sebelumnya dapat diketahui bahwa atlet perempuan mempunyai tingkat kebosanan yang lebih tinggi jika dibandingkan dengan atlet laki-laki dalam berbagai cabang olahraga olahraga (Cremades \& Wiggins, 2008). Selain itu atlet perempuan mempunyai kemampuan untuk mengatasi kesulitan, tekanan, penetapan tujuan, motivasi intrinsik dan persiapan mental yang lebih rendah jika dibandingkan dengan atlet laki-laki (Gábor, Géza, Miklós, József, 2009, p.229).

Secara teoritis cabang olahraga tim mempunyai masalah yang lebih kompleks. Sebagaimana yang dinyatakan oleh Husdarta (2010, p.106) "olahraga tim memerlukan penanganan yang lebih kompleks bila dibandingkan dengan olahraga individual". Selain harus mempersiapkan kemampuan individu, juga faktor kerjasama harus mendapat perhatian khusus, sehingga kegiatan latihan tim pada cabang olahraga tim mempunyai peranan yang sangat penting dalam upaya meningkatkan prestasi tim dalam pertandingan. Sementara itu atlet perempuan SEA Games Indonesia berasal dari berbagai daerah yang ada di Indonesia dengan berbagai macam karakteristik. Tentu bukan hal yang mudah untuk membangun sebuah tim dengan berbagai macam karakteristik psikologis yang dimiliki oleh atlet.

\section{SIMPULAN}

Berdasarkan hasil penelitian dan pembahasan yang telah diuraikan maka dapat disimpulkan bahwa: karakteristik psikologis atlet SEA Games Indonesia ditinjau dari cabang olahraga individu dalam kategori tinggi; karakteristik psikologis atlet SEA Games Indonesia ditinjau dari cabang olahraga tim dalam kategori tinggi; tidak ada perbedaan yang signifikan karakteristik psikologis atlet SEA Games Indonesia ditinjau dari cabang olahraga individu berdasarkan jenis kelamin; ada perbedaan yang signifikan karakteristik psikologis atlet SEA Games Indonesia ditinjau dari cabang olahraga tim berdasarkan jenis kelamin.

Berdasarkan hasil penelitian maka penulis mencoba untuk memberikan saran-saran kepada peneliti selanjutnya untuk mengembangkan item pertanyaan dalam kueisioner serta membahas secara mendalam setiap aspek psikologis dan setiap cabang olahraga.

\section{DAFTAR PUSTAKA}

Brewer, B. W. (2007). Psychology of sport injury rehabilitation. Handbook of sport psychology, 404-424.

Cashmore, E. (2006). Sport and exercise psychology: The key concepts. Routledge.

Cooke, A., Kavussanu, M., McIntyre, D., \& Ring, C. (2013). The effects of individual and team competitions on performance, emotions, and effort. Journal of Sport and Exercise Psychology, 35(2), 132-143.

Cremades, J. G., \& Wiggins, M. S. (2008). Direction and intensity of trait anxiety as predictors of burnout among collegiate athletes. Athletic Insight: The Online Journal of Sport Psychology, 10(2).

Deaner, R. O., Carter, R. E., Joyner, M. J., \& Hunter, S. K. (2015). Men are more likely than women to slow in the marathon. Medicine and science in sports and exercise, 47(3), 607.

Deaner, R. O., Balish, S. M., \& Lombardo, M. P. (2016). Sex differences in sports interest and motivation: An evolutionary perspective. Evolutionary Behavioral Sciences, 10(2), 73.

Dosil, J. (Ed.). (2006). The sport psychologist's handbook: A guide for sport-specific performance enhancement. John Wiley \& Sons.

Mills, G. E., \& Gay, L. R. (2016). Educational research: Competencies for analysis and applications. Upper Saddle Ridge, NJ: Pearson.

Gillet, N., \& Rosnet, E. (2008). Basic need satisfaction and motivation in sport. The Online Journal of Sport Psychology, 10(3). 
Gunarsa, S. D. (2008). Psikologi olahraga prestasi. Jakarta: Gunung Mulia.

Hergenhahn, B. R., \& Olson, M. H. (2015). Theories of learning. Prenada Media.

Hermawati, R. L. (2014). Profil perilaku sosial atlet cabang olahraga bela diri, cabang olahraga permainan dan cabang olahraga konsentrasi [dissertation]. Bandung: Universitas Pendidikan Indonesia.

Husdarta, H. J. S. (2010). Psikologi olahraga. Bandung: Alfabeta.

Katsikas, C., Argeitaki, P., \& Smirniotou, A. (2009). Performance strategies of greek track and field athletes: Gender and level differences. Biology of exercise, 5(1).

Komarudin, K. (2015). Psikologi olahraga. Bandung: PT. Remaja Rosdakarya.

Lane, A. (2008). Sport and exercise psychology. Journal of Sports Science and Medicine, 7(3), 421-421.

Mahoney, M. J., Gabriel, T. J., \& Perkins, T. S. (1987). Psychological skills and exceptional athletic performance. The sport psychologist, 1(3), 181-199.

Maksum, A. (2007). Kualitas pribadi atlet: Kunci keberhasilan meraih prestasi tinggi.
Anima, Indonesian Psychology Journal, 22(2), 108-115.

Parnabas, V. (2015). Identifying the gender differences on the level of competitive state anxiety and sport performance among track and field athletes. The International Journal of Indian Psychology, 2, 23-29.

Tenenbaum, G., \& Eklund, R. C. (Eds.). (2007). Handbook of sport psychology. John Wiley \& Sons.

Thibault, V., Guillaume, M., Berthelot, G., El Helou, N., Schaal, K., Quinquis, L., ... \& Toussaint, J. F. (2010). Women and men in sport performance: the gender gap has not evolved since 1983. Journal of sports science \& medicine, 9(2), 214.

Uçan, Y., \& Çağlayan, N. (2012). Comparison of self-esteem scores of individual and team sport athletes and nonathletes. Journal of Physical Education \& Sports Science/Beden Egitimi ve Spor Bilimleri Dergisi, 6(3).

Weinberg, R. S., \& Gould, D. (2011). Foundations of sport and exercise psychology. Champaign, IL: Human Kinetics. 